\title{
Viral Hepatitis B under Tenofovir in Ouagadougou (Burkina Faso)
}

\author{
Soudré Sandrine Marie-Odile Bobilwindé1*, Napon Fahosiata ${ }^{1}$, Zoungrana Steve Léonce ${ }^{2}$, \\ Ouattara Zanga Damien2, Koura Mali33, Guingané Nanelin Alice ${ }^{4}$, Somda Sosthène5, \\ Coulibaly Aboubacar5, Beni Da Nathalie1, Salou Rodrigue1, Bougouma Alain5, \\ Sombié Arsène Roger ${ }^{5}$
}

\begin{abstract}
${ }^{1}$ Hepato-Gastroenterology Unit of the University Hospital Tengandogo, Burkina Faso, Africa ${ }^{2}$ Hepato-Gastroenterology Unit of the University Hospital Ouahigouya, Burkina Faso, Africa ${ }^{3}$ Gastroenterology Service of the University Hospital Souro Sanou, Bobo-Dioulasso, Burkina Faso, Africa ${ }^{4}$ Gastroenterology Service of the University Hospital Bogodogo, Ouagadougou, Burkina Faso, Africa ${ }^{5}$ Gastroenterology Service of the University Hospital Yalgado Ouédraogo, Ouagadougou, Burkina Faso, Africa Email: *sandysoudre@yahoo.fr
\end{abstract}

How to cite this paper: Bobilwindé, S.S.M.-O., Fahosiata, N., Léonce, Z.S., Damien, O.Z., Mali, K., Alice, G.N., Sosthène, S., Aboubacar, C., Da Nathalie, B., Rodrigue, S., Alain, B. and Roger, S.A. (2021) Viral Hepatitis B under Tenofovir in Ouagadougou (Burkina Faso). Open Journal of Gastroenterology, 11, 141-150.

https://doi.org/10.4236/ojgas.2021.118015

Received: July 6, 2021

Accepted: August 24, 2021

Published: August 27, 2021

Copyright () 2021 by author(s) and Scientific Research Publishing Inc. This work is licensed under the Creative Commons Attribution International License (CC BY 4.0).

http://creativecommons.org/licenses/by/4.0/

\begin{abstract}
Introduction: The treatment of viral hepatitis B is based on nucleotide ana$\operatorname{logs}(\mathrm{s})$. In Burkina Faso, tenofovir is the most widely used because of its effectiveness and cost. The aim of this study was to describe viral hepatitis $B$ under tenofovir in Ouagadougou. Material and Method: This was a longitudinal study, carried out in the outpatient department of the University Hospital of Tengandogo from May 1, 2013 to September 31, 2020, i.e. a period of seven (07) years and five (05) months. All patients with chronic hepatitis B virus who had been taking tenofovir for at least one year were included in the study. Cases of hepatocellular carcinoma and co-infections with hepatitis D, $\mathrm{C}$ and human immunodeficiency viruses were excluded from the study. Results: Of 321 patients with hepatitis B, 120 were on tenofovir and 34 were included in our study. These were 24 men and 10 women with an average age of 39 years. Hepatitis B was most often discovered following systematic or voluntary screening $(44.1 \%)$ or pain in the right hypochondrium $(23.5 \%)$. The mean initial viral load was $7.9 \mathrm{log}$. Ten patients had moderate compliance and four were non-compliant. No side effects were reported in $91.3 \%$ of cases. The virologic response was complete in $72.7 \%$ of patients after six months. Nine out of ten patients showed a biochemical response after 16 months. A histological response was observed in 19/27 patients within a mean of 26.7 months. HBs seroconversion was found in $2 / 24$ patients. Conclusion: Tenofovir is effective in the treatment of viral hepatitis $\mathrm{B}$, but HBs seroconversion is rarely achieved.
\end{abstract}




\section{Keywords}

Viral Hepatitis B, Tenofovir, Compliance, Tolerance, Efficacy

\section{Introduction}

Viral hepatitis B is a major public health problem. According to the World Health Organization, 257 million people have chronic viral hepatitis B infection, causing an estimated 887,000 deaths in 2015 [1].

In Africa, the responsible virus is most often transmitted from mother to child during birth and childbirth. The risk of chronicity is therefore higher there with complications such as cirrhosis and hepatocellular carcinoma responsible for death [1].

Burkina Faso is located in the zone of high endemicity of hepatitis B. In fact, a study carried out in 2015 found a prevalence of 10.4\% [2]. Cirrhosis and liver cancer constitute $65 \%$ of the reasons for hospitalization in the hepato-gastroenterology department of the Yalgado Ouédraogo University Hospital Center in Ouagadougou. They are responsible for 3100 and 1400 deaths per year respectively [3].

For a long time, access to treatment for chronic viral hepatitis B was difficult. Nowadays, treatment is mainly based on nucleos $(\mathrm{t})$ idic analogues and immunomodulators. Thanks to the HIV/AIDS program, nucleos $(\mathrm{t}) \mathrm{idic}$ analogues are more available and accessible. Those with high barrier resistance should be prioritized [4]. Tenofovir, a reverse transcriptase inhibitor, is one of them and is the most effective and widely used treatment [5]. The aim of antiviral therapy is to stop the inflammatory process in the liver which can lead to cirrhosis or hepatocellular carcinoma. The objective is therefore the normalization of liver tests, improvement of liver histology, $\mathrm{HBe}$ seroconversion in $\mathrm{HBeAg}$ positive patients, and ideally $\mathrm{HBs}$ seroconversion [6]. Very few studies to assess the evolution of chronic viral hepatitis B under tenofovir in Burkina Faso have been carried out. Our study aimed to study the treatment of chronic viral hepatitis B with tenofovir disoproxil at Tengandogo University Hospital.

\section{Patients and Methods}

This was a longitudinal study carried out in the outpatient department of Tengandogo University Hospital, from May 1, 2013 to September 31, 2020, for a period of seven (07) years and five (05) months.

Patients of all ages, sexes, origins and socio-professional categories with viral hepatitis B who had been taking tenofovir for at least one year were included in the study.

Patients with hepatocellular carcinoma or coinfection (hepatitis B virus and hepatitis $C, D$ and human immunodeficiency virus) were excluded from the study.

HBsAg and HBVDNA were tested every six months to a year, as was alanine 
amino transferase (ALAT). An ALT was considered high when it was above twice the upper limit of normal. An initial abdominal ultrasound was performed then every six months to a year. The Fibrometer ${ }^{\circledR}$ and/or Fibroscan ${ }^{\circledR}$ were performed once a year to assess fibrosis and activity. Antiviral treatment was instituted for all patients with a viral load greater than $2000 \mathrm{IU} / \mathrm{ml}$ and/or activity of at least A2 and/or fibrosis of at least F2 on the METAVIR grid at histology or during the Fibrometer ${ }^{\circledR}$ and/or Fibroscan ${ }^{\circledR}$. Complementary examinations (biology, imaging) and treatment were very often the responsibility of the patient. The information was collected from the computerized and handwritten medical records of the patients on a collection sheet. Patients were contacted by phone to assess adherence to therapy.

Data were entered and analyzed using Microsoft Word software, EPI INFO 7.2. Statistical comparisons were made using $\mathrm{chi}^{2}$ tests with a significance level $\mathrm{p}$ $=0.05$.

The operational definitions were:

- Virological response: may be complete (undetectable HBV-DNA dating no longer than one year), partial (decrease in DNA $>2 \log$ copies $/ \mathrm{ml}$ ) or inadequate (decrease $<2 \log$ copies $/ \mathrm{ml}$ )

- Biochemical response: normalization of transaminases

- HBe seroconversion: disappearance of $\mathrm{HBe} \mathrm{Ag}$ and appearance of anti-HBe antibody

- HBs seroconversion: disappearance of HBs Ag and appearance of anti-HBs antibody

- Histological response: decrease in necrotico-inflammatory activity by at least two points in the histological activity index without degradation of the fibrosis score

- Treatment compliance: it was assessed during the interrogation

Total compliance: no forgetting;

Moderate compliance: overall compliance with catches over the last four weeks. Non-compliance: rarely taken or stopped the last four weeks.

The study was authorized by the management of Tengandogo University Hospital. The confidentiality of the information collected was respected.

\section{Results}

\subsection{Sociodemographic Characteristics}

From $05 / 01 / 2013$ to $09 / 30 / 2020$, that to say. seven (07) years and five (05) months, out of 3499 patients seen in hepato-gastroenterology, 403 (11.5\%) were seen for hepatitis with 321 cases of hepatitis B (79.6\%). One hundred and twenty (120) patients were on tenofovir and 34 were included in our study, that to say. $28.3 \%$ of patients on tenofovir. There were 24 men and 10 women; i.e. a sex ratio of 2.4. The average age of our patients was 39 years with extremes of 19 and 66 years. The 30 to 39 age group followed by the 40 to 49 age group were the most prevalent with 15 and 10 cases, respectively. Civil servants and infor- 
mal sector actors were the most encountered (18 and 6 cases). Twenty-five patients were in a relationship. In $85.3 \%$ of the cases, the patients resided in urban areas.

\subsection{Clinical Features}

Our sample consisted of 32 cases of chronic hepatitis and 02 cases of cirrhosis.

Ten patients had a family history of viral hepatitis B; four with hepatocellular carcinoma of viral B etiology and three with viral B cirrhosis.

Among the couple patients (25), partner screening was performed in 23 patients, twenty tested negative and two positive for HBsAg; the HIV status was not specified in the other. The twenty HIV-negative spouses were fully vaccinated or in the process of being vaccinated.

Twenty-nine patients had children and their HIV status was specified in 26 of them. Five patients had at least one child tested positive; in 5 others the serological status of the children was not investigated. It was unspecified in 3 others and negative in 16 .

Fourteen patients had used herbal medicine.

Viral hepatitis B was discovered during systematic or voluntary screening in 15 patients or with pain in the right hypochondria (8 cases). No functional signs were found in 23 patients.

Thirty-three patients were in good general condition and altered in the last.

In our study population, 12 of the 26 patients were overweight or obese for whom the body mass index was specified.

Twenty-seven (79.4\%) of our patients presented no physical signs.

Our population had an alanine amino transferase (ALT) mean of $0.9 \mathrm{~N}$ with extremes of $0.3 \mathrm{~N}$ and $2.2 \mathrm{~N}$. In patients with chronic viral hepatitis B, an ALT mean of $0.9 \mathrm{~N}$ with extremes of $0.3 \mathrm{~N}$ and $2.2 \mathrm{~N}$ were found and those with cirrhosis had ALTs at $0.5 \mathrm{~N}$ and $1.6 \mathrm{~N}$.

For aspartate amino transferase (ASAT), an average of $0.9 \mathrm{~N}$ with extremes of $0.3 \mathrm{~N}$ and $2.1 \mathrm{~N}$ was found. Patients with chronic hepatitis B had a mean of $0.8 \mathrm{~N}$ with extremes of $0.3 \mathrm{~N}$ and 1.6 N. Cirrhotic patients had $1.5 \mathrm{~N}$ and $2.1 \mathrm{~N}$ ASTs.

The mean initial viral load was $7.9 \mathrm{log}$ with extremes of $1.7 \mathrm{log}$ and $8.9 \mathrm{log}$. It was greater than $4 \log (2000 \mathrm{IU} / \mathrm{ml})$ in $66.7 \%$ of cases. Patients with chronic hepatitis B had an average viral load of $7.9 \mathrm{log}$ with extremes of $1.7 \mathrm{log}$ and $8.9 \mathrm{log}$ and those with cirrhosis had viral loads of $7.9 \log$ and $8.6 \mathrm{log}$, i.e. an average of $8.4 \mathrm{log}$, with a p-value of 0.3 .

Nine of the twelve patients tested initially had a pre-C mutant virus. Like those with wild virus, they had an average of $0.9 \mathrm{~N}$ for ALT. The mean viral load in mutant virus hepatitis cases was $7.7 \mathrm{log}$ with extremes of 1.7 and $8.6 \mathrm{log}$. In the wild virus cases, the mean viral load was $8.6 \log$ with extremes of 7.9 and 8.9 log. Abdominal ultrasound was initially performed in 22 patients and there was no liver damage in 17 patients, three had fatty liver disease, one had an irregular liver, and one had an appearance of cirrhosis. 
Fibrosis was quantified in 27 patients using the fibrometer ${ }^{\circledR}$ and/or fibroscan

${ }^{\circledR}$ and stage 2 fibrosis was found in 14 people. Four patients had severe fibrosis (F3-F4).

\subsection{Assessment of Compliance, Safety and Efficacy of Treatment of Patients with Viral Hepatitis B under Tenofovir Disoproxil Fumarate}

The mean duration of treatment in our population was 34.3 months with extremes of 12 and 74 months.

During our study, $52.9 \%$ or $18 / 34$ patients had to interrupt their treatment: eleven due to a break in the product at the Central Purchase of Generic Essential Medicines (CAMEG), no reason for three others, two by incomprehension, one voluntarily and the other for HBs seroconversion.

Ten patients had moderate compliance and four were non-compliant.

Thirty-one people had no side effects. One case of abdominal pain, one case of diarrhea and one case of bone pain have been reported.

The virological response at six months was complete in $72.7 \%$ of cases $(24 / 33)$, inadequate in $18.2 \%$ of cases (6/33), partial in $9.1 \%$ of cases $(3 / 33)$ and not evaluated in one patient.

It was complete in two thirds of patients (6/9) with mutant virus, partial or inadequate in the remaining third.

In patients with wild-type virus, a complete response was found in one third and an inadequate response in the other two.

Compliance was moderate in two-thirds of the patients who had a partial virologic response. One of the patients (wild virus cirrhotic) with full compliance had an inadequate response. The second cirrhotic patient with mutant virus and moderate adherence also had an inadequate response. Nine out of ten patients evaluated had a biochemical response within an average of 16 months; including one of the patients with cirrhosis.

Improvement in fibrosis was observed within an average of 26.7 months in 19 of the 27 patients assessed. In the remaining eight, there was no histologicparamètresal response.

Among the three patients initially $\mathrm{HBeAg}$ positive, seroconversion was observed in only one and not evaluated in the others.

HBs seroconversion was found in two patients at 66 and 72 months out of the 24 evaluated (Table 1 ).

An initially cirrhotic patient with moderate compliance, inadequate response, and $\mathrm{HBeAg}$ negative developed edema-ascitic syndrome after one year.

One HBeAg negative patient with a family history of viral hepatitis $B$, complete compliance, and complete virologic response developed cirrhosis after one year.

After an average of 26.7 months, $26.5 \%$ of our patients were lost to follow-up. No deaths were recorded in our study population. 
Table 1. Therapeutic aspects.

\begin{tabular}{|c|c|}
\hline Parameters & Values \\
\hline Duration of treatment (months) & $34.3(12-74)$ \\
\hline \multicolumn{2}{|l|}{ Therapeutic interruption } \\
\hline - Rupture at CAMEG & $11 / 18$ \\
\hline - No reason & $03 / 18$ \\
\hline - Misunderstanding & $02 / 18$ \\
\hline - Phytotherapy & $01 / 18$ \\
\hline - HBs seroconversion & $01 / 18$ \\
\hline \multicolumn{2}{|l|}{ Therapeutic adherence $\mathrm{n}(\%)$} \\
\hline - Total & $20(58.8)$ \\
\hline - moderate & $10(29.4)$ \\
\hline - Non compliance & $04(11.8)$ \\
\hline \multicolumn{2}{|l|}{ Virological response at 06 months } \\
\hline - Complete & $24 / 33$ \\
\hline - Partial & $03 / 33$ \\
\hline - Inadequate & $06 / 33$ \\
\hline Biochemical response & $09 / 10$ \\
\hline Histological response & $19 / 27$ \\
\hline HBe seroconversion & $01 / 03$ \\
\hline HBs seroconversion & $02 / 24$ \\
\hline
\end{tabular}

\section{Discussion}

From this study, it emerged that the average age of patients at the time of diagnosis was 39 years. Targeted screening campaigns (unvaccinated subjects) could allow a diagnosis in younger patients. The sex ratio is 2.4 ; for a population which is predominantly female (51.7\%) [7]. This could be explained by the greater tendency of men to consult and be tested (men having greater financial power than women in our context). It could also suggest higher transmission of the virus in boys during childhood linked to greater horizontal transmission during their more important play activities. Seventeen (17) patients had a family history of hepatopathy or even hepatocellular carcinoma of viral B etiology, hence the importance of family screening. All HIV-negative spouses had received at least one dose of the vaccine and 20/25 of the children were fully immunized. These high proportions of screening in our study could be explained by the increase in awareness campaigns, but also by the level of education and the socio-economic level of our population. The low percentage of complete vaccination of children and spouses is linked to the cost of the vaccine, associated with the age of children above the introduction of the vaccine in the Expanded Program on Immunization. Fourteen (14) of our patients had used herbal medicine. Herbal 
cine can cause liver and kidney toxicity, encouraging discontinuation of tenofovir therapy. Raising patient awareness and better collaboration between practitioners and traditional therapists could lead to better patient care.

Eleven (11) patients had interrupted their treatment at some point due to a rupture of tenofovir at the Central Purchase of Generic Essential Medicines (CAMEG), no reason for three others and two due to incomprehension. Granting the authorization to sell tenofovir disoproxil to town pharmacies may help somewhat to resolve the supply difficulties; also better information for patients through the organization of therapeutic education sessions could lead to better adherence to treatment.

Thirty-one people had no side effects. Tenofovir disoproxil has a good safety profile.

The virological response was complete in $72.7 \%$ of cases (24/33) at 6 months. Two thirds of the patients who had a partial virologic response had moderate compliance. This demonstrates the need to improve patient compliance. The two patients with cirrhosis had an inadequate virologic response. This could suggest that tenofovir is less effective in the stage of cirrhosis. However, their very low number, the moderate observance of one, does not allow us to conclude.

The majority of our patients had normal transaminases $(0.9 \mathrm{~N})$ when treatment was initiated. This is due to immune tolerance or weak immune response due to infection acquired at birth or in infancy, the most common mode of transmission in sub-Saharan Africa [8].

Nine out of ten patients evaluated had a biochemical response within an average of 16 months.

Improvement in fibrosis was observed within an average of 26.7 months in 19 of the 27 patients assessed; or $70.4 \%$ of cases. This reflects the effectiveness of tenofovir.

Only three patients had HBeAg-positive chronic viral hepatitis B. Hepatitis B due to the pre-C mutant is now widespread in populations around the Mediterranean basin, in Africa, Asia and Europe [9] [10].

During our follow-up, we found an oedemato-ascitic syndrome in an initially cirrhotic patient with moderate compliance, an inadequate response and negative $\mathrm{HBeAg}$.

One HBeAg negative patient with a family history of viral hepatitis $\mathrm{B}$, complete compliance, and complete virologic response developed cirrhosis.

The severity of viral B hepatopathies and the onset of cirrhosis and its complications are precipitated by the persistence of viral multiplication, which generates necrotico-inflammatory activity and is responsible for morbidity and mortality [11].

After an average of 26.7 months, $26.5 \%$ of our patients were lost to follow-up. Several reasons could be the cause: in particular: financial, geographical accessibility, requisition of the hospital center for the management of COVID19.

In comparison with other studies, our results are similar to that of Sombie in 
Burkina, which found total compliance in $68 \%$ of cases and moderate in $14.4 \%$ of patients [11].

The treatment interruption was often due to: forgetting to take the treatment (more frequent at the beginning), lack of money, drug stock-outs at CAMEG; according to Sombié [11].

Fourteen patients (14/34) did not have full compliance, results similar to a study carried out in Burkina-Faso [11].

Six-month virosuppression was achieved in $24 / 33$ (72.73\%) of cases. These results are inferior to many studies [11] [12] [13] but these studies mostly evaluated it over longer periods. Thus, Sombié reported virosuppression varying from $70 \%$ to $90 \%$ between one year and three years, and more than $90 \%$ after five years. Butti in Spain; 99.3\% virosuppression at seven years [12]. The extension of the follow-up of our patients could allow us in the future to compare our results with these authors.

Nineteen out of 27 patients presented a histological response. A study carried out in Burkina-Faso found higher proportions [14].

Two out of 24 patients presented with HBs seroconversion. Numerous studies have highlighted this low seroconversion [9] [15] [16] [17] [18] [19].

The main limitation of this study is the size of our sample (34) which could be due to the retrospective nature of the collection which was a source of information bias, the high cost of the initial assessment (very few with health coverage) and the use of other therapeutic alternatives.

\section{Conclusion}

Our study shows that tenofovir is effective in the treatment of chronic hepatitis $B$, with excellent tolerability. Once the treatment indication has been made, the patient must take part in the therapeutic project and receive complete information on the advantages and disadvantages of indefinite treatment. The majority of our patients were $\mathrm{HBe}$ antigen negative, if the chances of HBs seroconversion exist, they remain very low. More than one in 4 patients were lost to follow-up after 26.7 months, it would be interesting to carry out further investigations to better understand the reasons and to try to remedy them.

\section{Conflicts of Interest}

The authors declare no conflicts of interest regarding the publication of this paper.

\section{References}

[1] OMS. (2020) Principaux repères sur l'hépatite B. https://www.who.int/fr/news-room/fact-sheets/detail/hepatitis-b

[2] Diarra, B., Yonli, A.T., Ouattara, A.K., et al. (2018) World Hepatitis Day in Burkina Faso, 2017: Séroprévalence and Vaccination against Hepatitis B Virus to Achieve the 2030 Elimination Goal. Virology Journal, 15, Article No. 121. https://doi.org/10.1186/s12985-018-1032-5 
[3] Abga, T.A. (2017) Les hépatites B et C favorisent grandement le cancer du foie au Burkina Faso (médecins). http://news.aOuaga.com/h/108644.html

[4] de la Santé, M. (2019) Normes et protocoles de prise en charge des Hépatites virales au Burkina Faso. Ouagadougou, Burkina Faso.

https://scge-cm.com/download/Normes\%20et\%20protocoles\%20de\%20Prise $\% 20$ en \%20charge\%20HV\%20au\%20BF\%20Vf\%202019.pdf

[5] Smith, P. and Namjilsuren, T.O. (2017) Éliminer l'hépatite: La réponse de l'OMS. https://www.who.int/fr/news/item/27-07-2017-eliminate-hepatitis-who

[6] Doerig, C., Antonino, A., Pache, I., et al. (2010) Prise en charge de l'hépatite B chronique : Un défi en évolution constante. Revue Médicale Suisse, 6, 168-173.

[7] Institut National de la Statistique et de la Démographie (2019) Cinquième Recensement Général de la Population et de l'Habitation du Burkina Faso. Résultats Préliminaires. Ouagadougou, Burkina Faso.

https://www.insd.bf/contenu/documents_rgph5/RAPPORT_PRELIMINAIRE_RGP $\underline{\text { H_2019.pdf }}$

[8] Maddrey, W. (2000) Hepatitis B: An Important Public Health Issue. Journal of Medical Virology, 61, 362-366. https://doi.org/10.1002/1096-9071(200007)61:3<362::AID-JMV14>3.0.CO;2-I

[9] Sombié, R., Sangaré, L., Guingané, A., et al. (2015) Traitement de l’hépatite B chronique par les analogues nucléos(t)idiques. Journal Africain dépato-Gastrotérologie, 9, 114-118. https://doi.org/10.1007/s12157-015-0601-4

[10] Dray-Spira, R., Sogni, P., Lert, F., et al. (2015) Caractéristiques des personnes originairesd'Afrique subsaharienne suivies pour une hépatite $B$ chronique en Ile-de-France en 2012-2013: Données de l'enquête ANRS-Parcours. BEH, 341-347.

[11] Sehonou, J., Kpossou, A., Guido, S., et al. (2018) Effectiveness and Safety of Tenofovir Disoproxil Fumarate in Patients Treated for Hepatitis B in the National University Hospital of Cotonou. Open Journal of Gastroenterology, 8 213-222. https://doi.org/10.4236/ojgas.2018.86024

[12] Diallo, S., Bassene, M., Gueye, M., et al. (2018) Hépatite virale B: Aspects cliniques, paracliniques et évolutifs dans le service d'Hépato Gastroentérologie del'Hôpital Aristide Le Dantec: à propos de 728 cas. The Pan African Medical Journal, 31, Article No. 82.http://www.panafrican-med-journal.com/content/article/31/82/full/ https://doi.org/10.11604/pamj.2018.31.82.14725

[13] Sombié, R., Bougouma, A., Diallo, O., et al. (2010) Hépatite B chronique : Aspects épidémiologique, diagnostique, thérapeutique et évolutif au centrehospitalier universitaire Yalgado Ouédraogo de Ouagadougou. Journal Africain d'épato-Gastrotérologie, 4, 3-10. https://doi.org/10.1007/s12157-009-0137-2

[14] Villani, R., Forlano, R., Vendemiale, G., et al. (2015) Analogs in the Treatment of Chronic Hepatitis B: Real Life Experience with Tenofovir and Entecavir. Clin Clinical Management Issues, 9 57-62. https://doi.org/10.7175/cmi.v9i2.1192

[15] Somda, K.S., Sermé, A.K., Coulibaly, A., et al. (2016) Treatment of HBeAg-Negative Chronic Hepatitis B Patients with Nucleos(t)ide Analogues in Burkina Faso. Open Journal of Gastroenterology, 6, 387-396. https://doi.org/10.4236/ojgas.2016.612041

[16] Buti, M., Tsai, N., Petersen, J., et al. (2015) Seven-Year Efficacy and Safety of Treatment with Tenofovir Disoproxil Fumarate for Chronic Hepatitis B Virus Infection. Digestive Diseases and Sciences, 60, 1457-1464.

https://link.springer.com/article/10.1007/s10620-014-3486-7 https://doi.org/10.1007/s10620-014-3486-7

[17] Edmunds, W., Medley, G., Nokes, D., et al. (1996) Epidemiological Ptterns of Hepa- 
titis B Virus (HBV) in Highly Endemic Areasr. Epidemiology \& Infection, 117, 313-325. https://doi.org/10.1017/S0950268800001497

[18] Lovett, G., Nguyen, T., Iser, D., et al. (2017) Efficacy and Safety of Tenofovir in Chronic Hepatitis B: Australian Real World Experience. World Journal of Hepatology, 9 48-56. https://doi.org/10.4254/wjh.v9.i1.48

[19] Zheng, S., Liu, L., Lu, J., et al. (2019) Efficacy and Safety of Tnofovir Dsoproxil Fumarate in Chinese Patients with Chronic Hepatitis B Virus Infection: A 2-Year Prospective Study. Medicine, 98, e7590.

https://doi.org/10.1097/MD.0000000000017590 